\title{
Improved epicentral relocation in the offshore Campos basin, SE Brazil, with the RSTT 3D model
} \author{
Antonio Ortolan ${ }^{\mathrm{d}}$ \\ a Seismology Center, IAG-USP, São Paulo, Brazil \\ ${ }^{\mathrm{b}}$ IGCE-UNESP, Rio Claro, SP, Brazil \\ ${ }^{\mathrm{c}}$ Schlumberger, Houston, USA \\ d Petrobras, EXP/GEOF/AG, Rio de Janeiro, Brazil
}

Felipe dos Anjos Neves ${ }^{\mathrm{a}}$, Marcelo Assumpção ${ }^{\mathrm{a}, *}$, João Carlos Dourado ${ }^{\mathrm{b}}$, Frank Le Diagon ${ }^{\mathrm{c}}$,

\section{A R T I C L E I N F O}

\section{Keywords:}

Continental shelf

Regional 3D epicentral location

RSTT

\begin{abstract}
A B S T R A C T
Earthquake location on the continental shelf is often poor because: a) the seismic stations are mainly located on the continent, to one side of the epicenter (which means that any error in the velocity model causes a large epicentral error), and b) 1D models are commonly used in a region with strong lateral variations in the crustal structure. We tested the use of the 3D regional seismic travel time (RSTT) model to relocate an event of magnitude $3.8 \mathrm{~m}_{\mathrm{b}}$ that occurred on July the $1 \mathrm{st}, 2010$, in the Campos basin, southeast (SE) Brazil. This event was also recorded by a seismic vessel, which allowed an estimate of the azimuth of the incoming P-waves. The new location based on the 3D model is more consistent with the data recorded by the streamers, which shows that the use of 3D RSTT models can improve earthquake locations offshore. Several other events in the SE offshore basins were relocated with the 3D RSTT model, which confirmed the trend of epicenters lying beneath the continental slope where sediment thickness tends to be highest.
\end{abstract}

\section{Introduction}

The causes of intraplate seismicity have been the subject of intense debate (Li et al., 2009), and the explanation of slow strain accumulation until the rock strength is reached, commonly applied to plate-boundary activity, has been disputed (Calais et al., 2016). Despite this debate, intraplate seismicity has been associated with areas of crustal weakness due to extensional deformation in the last major tectonism, such as continental failed rifts and offshore continental shelves (Schulte and Mooney, 2005). Most of the largest intraplate earthquakes worldwide have occurred in continental shelves (Johnston and Kanter, 1990; Schulte and Mooney, 2005).

In Brazil, the SE offshore region has a significant level of seismicity (Assumpção, 1998; Assumpção et al., 2011; 2014, 2016), which has been attributed to the combination of spreading stresses from continent/ocean transition and flexural stresses from sediment load, both favorably oriented with respect to the far-field regional stresses (Assumpção et al., 2014).

However, detailed studies of offshore seismicity are hampered due to the difficulty of accurately determining earthquake locations. The routine location of epicenters offshore is commonly based on seismic stations onshore and the use of simple, average 1D velocity models. Simple tests of different 1D models show that errors of about $\sim 100 \mathrm{~km}$ or more are possible (Assumpção, 1998). These errors are much larger than the errors given by the location routines, which do not take into account model uncertainties or non-linear uncertainty effects caused by arrival-time misfit.

3D models, such as regional seismic travel time (RSTT) (Myers et al., 2010), allow a better estimate of epicenters. However, 3D models must be calibrated and tested against well-known epicenters calculated independently (ground truth events), which are extremely rare in offshore areas. Fortunately, an event in the Campos basin, on July 1st, 2010, with a magnitude $3.8 \mathrm{~m}_{\mathrm{b}}$, was recorded during a 3D seismic survey carried out by the Western Neptune seismic vessel. The event was also felt at the Pampo and Enchova platforms (L. Paganelli, Petrobras, personal communication). Analysis of the earthquake signals recorded during the seismic survey can provide extra information, allowing us to check the accuracy of epicenter locations. We use this event to show that the RSTT model (which incorporates the crustal thickness map of Assumpção et al., 2013a,b) improves earthquake location in SE offshore Brazil. Large previous events (magnitudes above $3.2 \mathrm{~m}_{\mathrm{b}}$ ) are then relocated with the RSTT technique, showing more

\footnotetext{
* Corresponding author.

E-mail address: marcelo.assumpcao@iag.usp.br (M. Assumpção).
} 


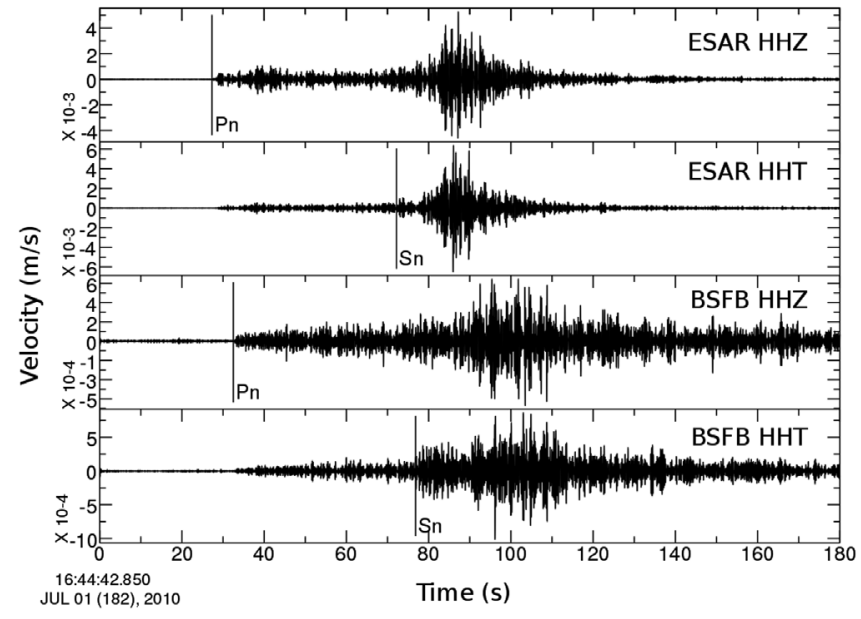

Fig. 1. Records with the Pn, shown in the HHZ vertical component, and the Sn waves, shown in the HHT transversal component, at the stations ESAR and BSFB of the event in the Campos Basin on 2010-07-01. We applied a band pass filter between 4 and $8 \mathrm{~Hz}$. All amplitudes are normalized.

effectively the trend of earthquake activity occurring along the continental slope.

\section{The event of 2010, July 01}

This event occurred in the Campos sedimentary basin, and was recorded by six regional stations (Figs. 1 and 2). Its magnitude was measured as $3.8 \mathrm{~m}_{\mathrm{R}}$. This is a regional magnitude scale using shortperiod P-waves, developed for the attenuation characteristics of the

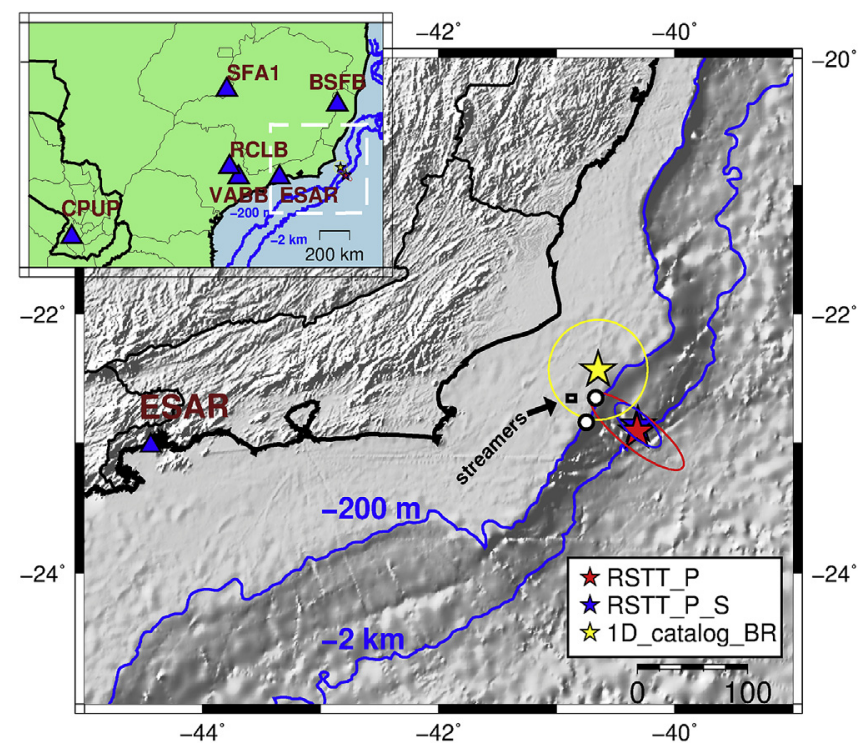

Fig. 2. Insert: Map of the regional stations (blue triangles) and the three epicenters from Table 1 . Thick and thin solid lines are country and state boundaries. Dashed line shows the area of the large map. Large map: Detail of the epicentral area. Stars and ellipses are epicenters and errors from Table 1 . The two white circles indicate the Anchova (north) and Pampo (south) platforms where the earthquake was felt. Small rectangle is the location of the streamers and Neptune vessel during the seismic survey (as seen in Fig. 3). The earthquake signals in the streamers show the seismic waves arriving from the SE, more consistent with the RSTT epicenters compared with the location from the 1D model used in the Brazilian Seismic Catalog. The two solid blue lines are the $200 \mathrm{~m}$ and $2000 \mathrm{~m}$ bathymetry depicting the continental slope. (For interpretation of the references to color in this figure legend, the reader is referred to the web version of this article.)
Table 1

Epicenters of the 2010-07-01 event. Depth fixed at $10 \mathrm{~km}$. Model labels: 1D_catalog_BR $=$ NewBR as used in the Brazilian Bulletin; RSTT_P $=3 \mathrm{D}$ RSTT model with Pn; RSTT_P_S = 3D RSTT with Pn and Sn arrivals. erh is the epicentral uncertainty; $r m s$ is the average arrival-time residual.

\begin{tabular}{llllll}
\hline Model & Latitude & Longitude & Erh $(\mathrm{km})$ & Origin $16 \mathrm{~h} 44 \mathrm{~m}$ & Rms (s) \\
\hline 1D_catalog_BR & -22.43 & -40.65 & 43 & $19.0 \mathrm{~s}$ & 2.8 \\
RSTT_P & -22.91 & -40.32 & 33 & $15.4 \mathrm{~s}$ & 1.0 \\
RSTT_P_S & -22.86 & -40.31 & 18 & $15.8 \mathrm{~s}$ & 1.2 \\
\hline
\end{tabular}

Brazilian lithosphere (Assumpção, 1983), and is consistent with the 1-s teleseismic $m_{b}$ scale (Assumpção et al., 2014). The routine earthquake location with the average 1D model used for Brazilian events (1D-catalog_BR, first row in Table 1) gives the epicenter in the shallow part of the continental shelf. The few available stations do not allow any resolution for the hypocentral depth, which was fixed at $10 \mathrm{~km}$.

Determining the locations of earthquakes with 3D models usually requires ray tracing through complex structures, which can be time consuming for routine analyses. RSTT is a simplified scheme to calculate traveltimes for regional distances (less than $15^{\circ}$ ) (Myers et al., 2010). The RSTT model is composed of a global tessellation of nodes with approximately $1^{\circ}$ spacing. The $1 \mathrm{D}$ models are interpolated to render a 3D model of the crust and a laterally varying upper mantle. Each model has up to seven layers in the crust and a simplified upper mantle structure consisting of a Pn velocity just below the Mohorovičić discontinuity (Moho) and a constant velocity gradient.

We used the last global RSTT model (file named

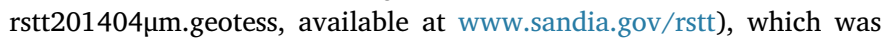
updated in South America using the crustal thickness model of Assumpção et al. (2013a,b). In the Santos and Campos basin, offshore SE Brazil, the 2013 crustal model used mainly the crustal thicknesses given by the compilation of Zalan et al. (2011). The earthquake location program was iLoc as used by the International Seismological Centre (ISC) (Bondar and Storchak, 2011), which was adapted to include traveltimes from the RSTT model (http://www.seismology.hu/data/iLoc/ ).

We calculated two epicenters: one using only $\mathrm{P}$ arrivals up to distances of $15^{\circ}$ (epicenter RSTT_P in Table 1), and the other using both $\mathrm{P}$ and $S$ arrivals, also limited to stations within $15^{\circ}$ (RSTT_P_S in Table 1). As shown in Fig. 2, both epicenters using the RSTT model place the epicenter about $70 \mathrm{~km} \mathrm{SE}$ of the epicenter calculated with the 1D model for Brazil (NewBR), which used an average crustal thickness of $40 \mathrm{~km}$. Clearly, the crustal thickness variations along the continental margin have a strong influence in the epicenter determination.

\section{Observations of the seismic survey}

When the 2010 earthquake occurred, a seismic survey was being carried out for Petrobras by the Western Neptune seismic vessel (Fig. 3). The survey location is shown by the small rectangle in Fig. 2. Two consecutive shot gathers recorded by the seismic vessel's streamers reveal waves generated by the earthquake, easily identified by their lower frequency content (about 4-5 Hz) and longer duration, in additional to the seismic waves induced by the vessel's source arrays. Fig. 4 shows the seismic section of Shots 2137 (just before the earthquake) and 2138 (during the event). For simplicity, we call these two shots as " 1 " and " 2 ".

\section{Streamer data array analysis}

We estimated the velocity and direction of the incoming earthquake signal using a beam-forming technique, by using the array processing routine of ObsPy (Megies et al., 2011). First, we applied an F-K filter to the shot records to remove the reflected signal energy from the ship's 


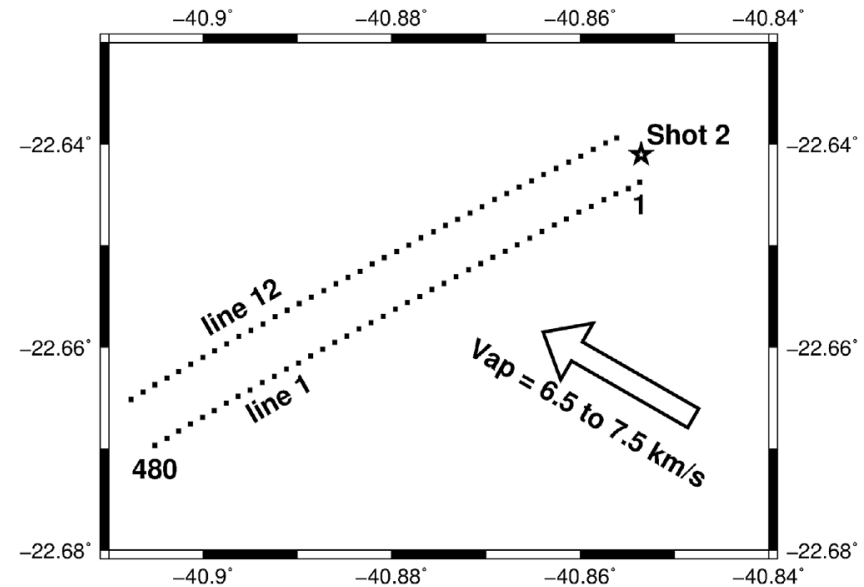

Fig. 3. Geometry of the seismic lines. Only lines 1 and 12 are shown. The dots indicate one hydrophone out of every 12 . The star is the source location.

source array. A band-pass filter between 1 and $8 \mathrm{~Hz}$ was then applied to further reduce the shot signal and isolate the lower-frequency earthquake signal, as shown in Fig. 4c. 252 sensors were selected (21 from each of the 12 cables) for the array analysis. All azimuths and slownesses were searched to retrieve the best stacked signal using 1-s time windows in steps of $0.05 \mathrm{~s}$ along the whole 6-s record.

The results (Fig. 5) show that the incoming direction of the waves (back azimuths) are mainly in the range $110^{\circ}-130^{\circ}$. The slownesses tend to be in the range $0.13-0.15 \mathrm{~s} / \mathrm{km}$ (approximate velocities of $6.5-7.5 \mathrm{~km} / \mathrm{s})$. Given the distance of the hypocenter $(70-100 \mathrm{~km})$, these velocities correspond to a P-wave train. The signal with the highest energy has a back azimuth of $120^{\circ}$ (Fig. 5b), which is more consistent with the epicenter location calculated by the RSTT than the initial epicenter given by the Brazilian Bulletin (Fig. 2).

Array analyses of Shot 3, which also recorded the earthquake signal, give similar results and confirm the consistency of the RSTT epicenters.

\section{Map of relocated epicenters in the offshore Santos and Campos basins}

We used the RSTT model to relocate all larger earthquakes in the Santos and Campos basins with at least five available P-wave readings

a)

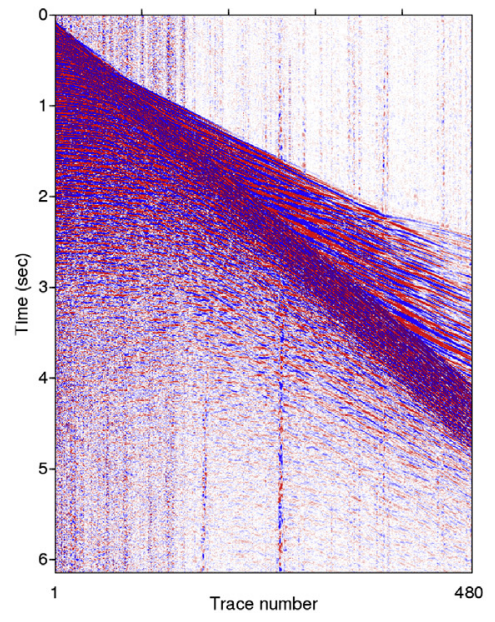

b)

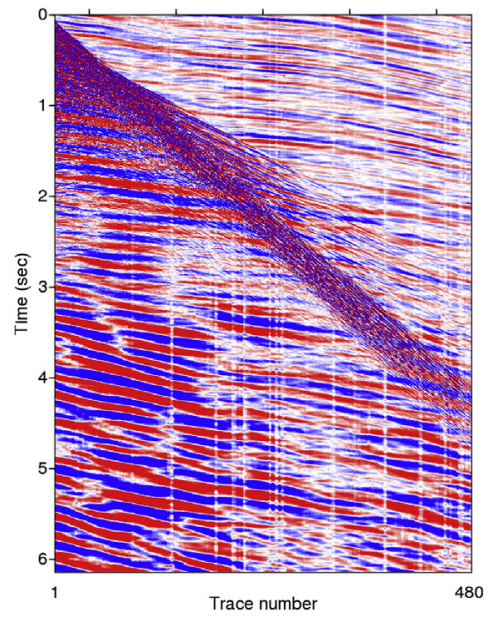

(Table 2). Fig. 6 compares the results of the three epicenters: the previous catalog location with the 1D model, the RSTT location with P readings only, and the RSTT location with $\mathrm{P}$ and $\mathrm{S}$ readings. Here in this paper, $\mathrm{P}$ and $\mathrm{S}$ readings/arrivals mean, respectively, $\mathrm{Pn}$ and $\mathrm{Sn}$ phases. Because depth is poorly resolved, it was fixed at $10 \mathrm{~km}$ a value close to the average depth of the few well located events using pP depth phases (Assumpção, 1998). Using 0 or $10 \mathrm{~km}$ depth changes the epicenters by less than about $15 \mathrm{~km}$, in general.

The large event of 2008 April 22 (Fig. 6), with a magnitude $5.0 \mathrm{~m}_{\mathrm{b}}$, was located by the ISC with 511 stations worldwide. Given the large number of teleseismic stations and the relatively small azimuthal gap, the epicentral error should be less than $20 \mathrm{~km}$, according to the criteria of Bondar et al. (2004). The RSTT location (using only continental stations up to $15^{\circ}$ distance) is in good agreement with this teleseismic epicenter, given the uncertainties of each determination. This means that the 2008 large event confirms the good performance of the RSTT locator for offshore SE Brazil, even when using stations only in the continent.

\section{Discussion and conclusions}

Besides the signal recorded during seismic surveys, the 2010 earthquake was also felt by people on the Enchova and Pampo platforms, which are about $40 \mathrm{~km}$ from the average RSTT epicenter. An earthquake onshore with magnitude $3.8 \mathrm{~m}_{\mathrm{R}}$ can be felt up to a distance of 30-90 km (Assumpção et al., 2014). If the attenuation of seismic waves offshore is not significantly different from that on the continent, we can say that the RSTT epicenters are also compatible with the event being felt at the two platforms.

The 2010 epicenter calculated with the RSTT model is much more consistent with the observations of the signals recorded by the streamers, compared with the location of the Brazilian Seismic Bulletin. This is an important result and shows that the RSTT model can significantly improve locations for offshore events in SE Brazil, a region with a high azimuthal gap and significant lateral variation. It is worth noting that the difference between the RSTT location and the previous epicenter (about $90 \mathrm{~km}$ ) is much larger than the standard errors given by each determination. This could be due to inaccurate assessment of pick and/ or model uncertainty and the non-linear relationship between event location and arrival-time residuals when an event is outside the network.

The RSTT relocated epicenters of all regionally recorded events c)

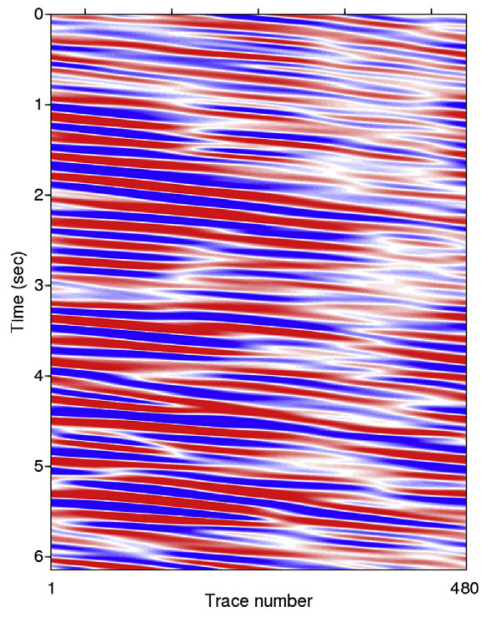

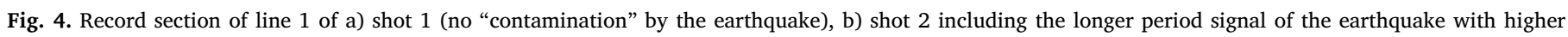

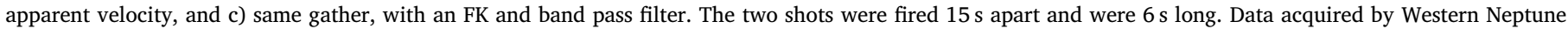
vessel. Shot 2 starts at time 16:44:37. 

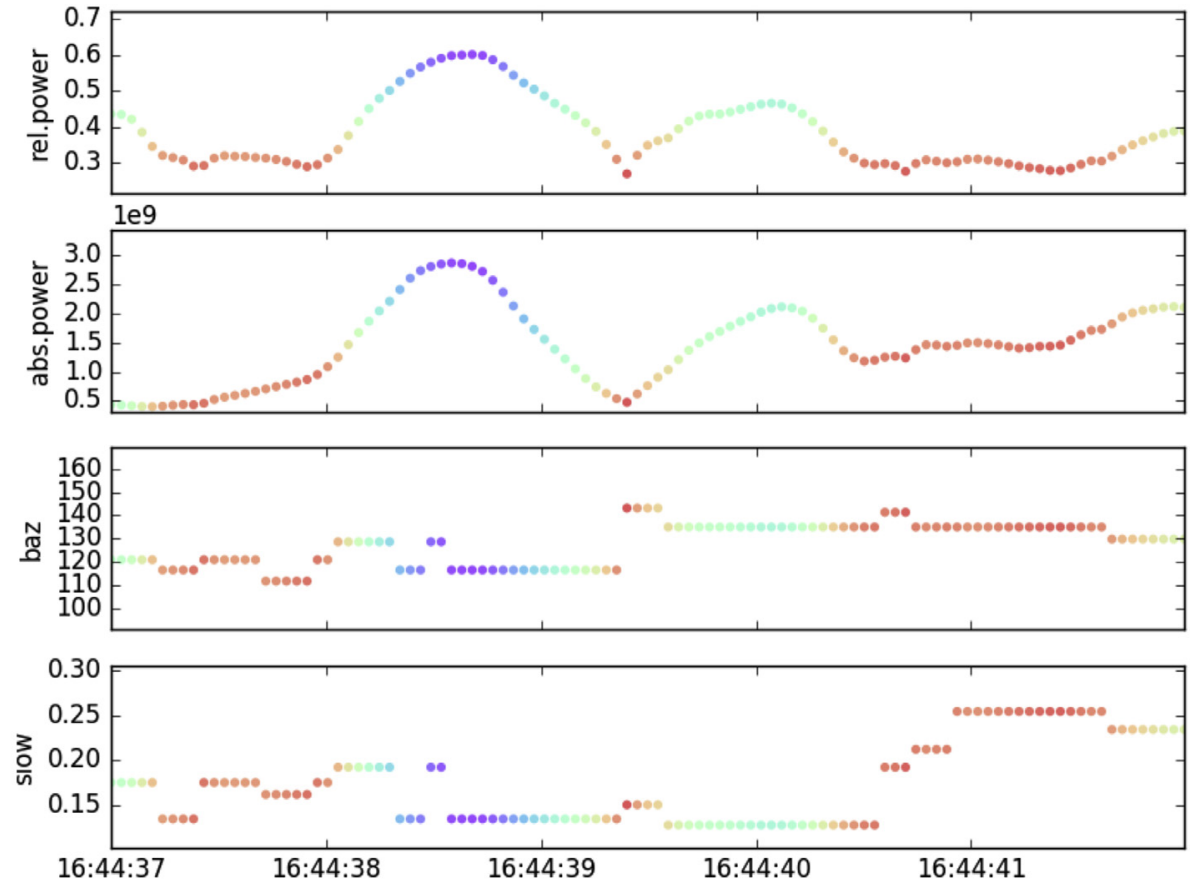

N
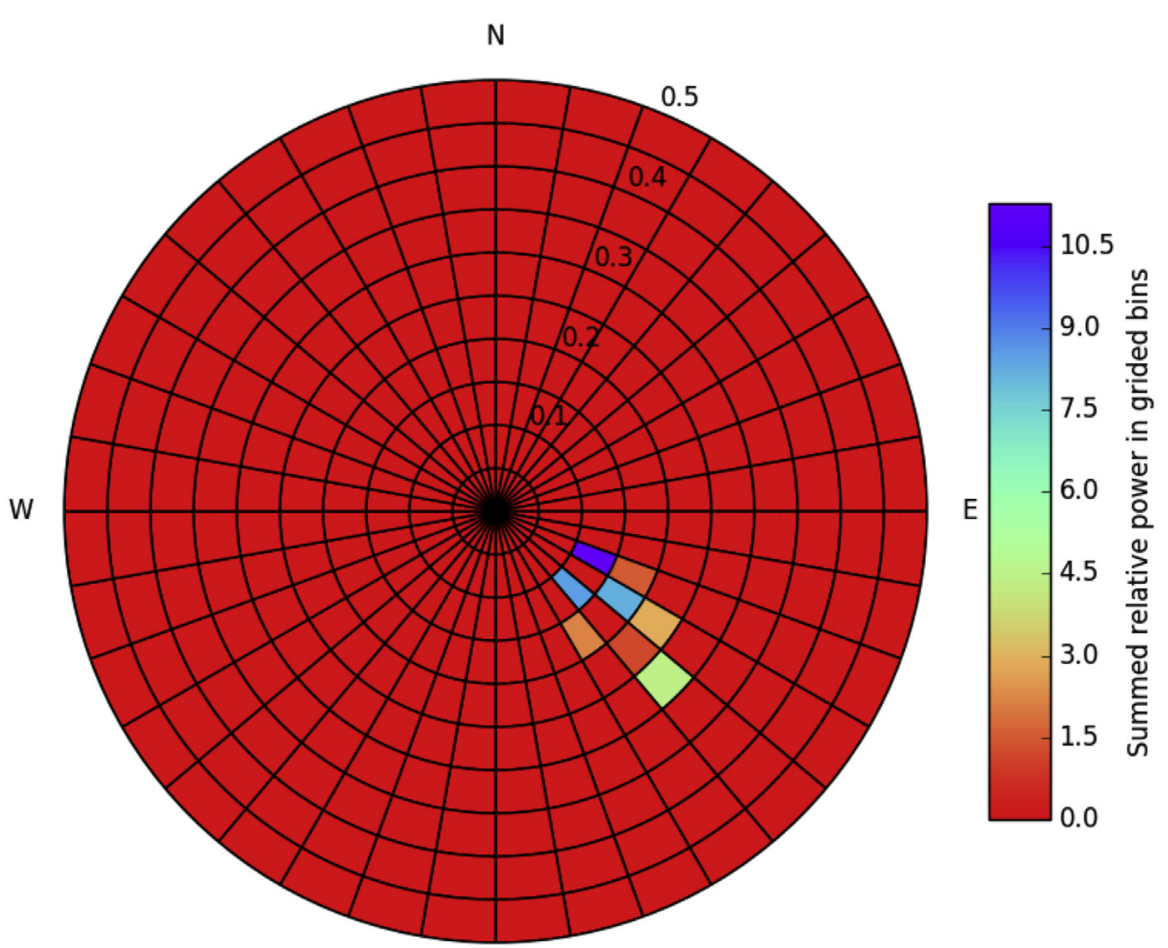

S

(Fig. 6) confirm the trend of seismicity occurring along the continental slope, indicated by the isopachs of 200 and $2000 \mathrm{~m}$ in Fig. 6. Except for two events (1992-December and 2002) which remained in the shelf, all other events stayed or were relocated to the continental slope. The continental slope is generally close to the thickest pile of sediments (Chang et al., 1992; Evain et al., 2015). That extra weight of sediments causes flexural stresses and contributes to the seismicity along the
Fig. 5. Array analysis of shot 2, after applying an F-K filter to remove the signal from the shot itself and enhance the signal from the earthquake. A bandpass filter $1-8 \mathrm{~Hz}$ was used before the array processing, which further reduces the signal from the boomer. The array processing was done with 21 traces from each of the 12 lines, chosen to sample the $6 \mathrm{~km}$ long line. A total of 252 traces were used. A sliding 1-sec long time window was used, with steps of $0.05 \mathrm{~s}$. (a) Results of the beam-forming along the $6 \mathrm{~s}$ records: signal power, back-azimuth ("baz") and slowness (s/ $\mathrm{km}$ ). The horizontal time axis shows the start of the sliding window. (b) Polar plot of the signal power (color scale) according to back-azimuth and slowness (plot radius). During the highest energy of the earthquake signal, the predominant back-azimuth is between $110^{\circ}$ and $130^{\circ}$, and the slowness tends to be in the range $0.13-0.15 \mathrm{~s} / \mathrm{km}$ (approximately $6.5-7.5 \mathrm{~km} / \mathrm{s}$ ) corresponding to P-wave velocities.

continental margin. This had been suggested in previous studies of focal mechanisms and seismotectonics offshore (Assumpção, 1998, Assumpção et al., 2011). The use of the RSTT model gives more confidence in the correlation of offshore epicenters with the continental slope and emphasizes the importance of flexural stresses in the continental shelf. 
Table 2

Large earthquakes in Santos and Campos basins between 1992 and 2016. Here, the epicenters with the RSTT model with Pn and Sn arrivals. Erh is the epicentral uncertainty; Rms is the average arrival-time residual. Depth fixed at $10 \mathrm{~km}$ for all events, except for the 2008/04/23 where $17 \mathrm{~km}$ was used (from pP by Assumpção et al., 2011).

\begin{tabular}{|c|c|c|c|c|c|c|}
\hline Event date (model RSTT_P_S) & Time (UTC) & Latitude & Longitude & $\operatorname{Mag}\left(\mathrm{m}_{\mathrm{R}}\right)$ & Erh $(\mathrm{km})$ & Rms (s) \\
\hline $1992 / 04 / 24$ & 03:09:32.18 & -26.69 & -45.92 & 3.7 & 26 & 0.7 \\
\hline $1992 / 12 / 09$ & $16: 20: 59.42$ & -25.03 & -46.41 & 3.4 & 23 & 0.9 \\
\hline $1993 / 05 / 21$ & 10:32:12.77 & -24.05 & -42.97 & 3.6 & 28 & 1.2 \\
\hline $1996 / 10 / 26$ & $20: 30: 18.31$ & -22.70 & -40.37 & 4.0 & 19 & 0.6 \\
\hline $1998 / 04 / 18$ & 02:32:17.61 & -24.83 & -44.34 & 3.4 & 21 & 1.1 \\
\hline $2002 / 06 / 04$ & $23: 27: 16.18$ & -24.87 & -45.90 & 3.7 & 13 & 1.7 \\
\hline $2008 / 04 / 23$ & 00:00:51.04 & -25.47 & -45.33 & 5.2 & 11 & 2.2 \\
\hline $2010 / 07 / 01$ & $16: 44: 15.78$ & -22.86 & -40.31 & 3.8 & 18 & 1.2 \\
\hline $2011 / 07 / 27$ & $18: 25: 57.20$ & -21.86 & -39.94 & 3.2 & 18 & 1.9 \\
\hline $2016 / 07 / 19$ & $15: 30: 48.04$ & -20.13 & -39.10 & 3.8 & 13 & 0.5 \\
\hline
\end{tabular}

a)

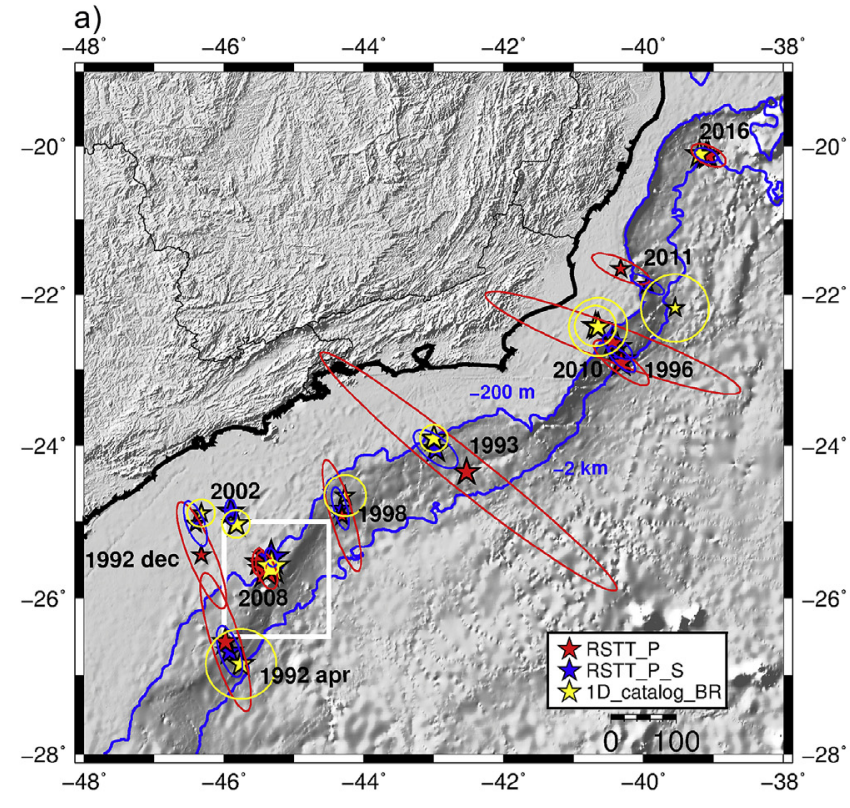

b)

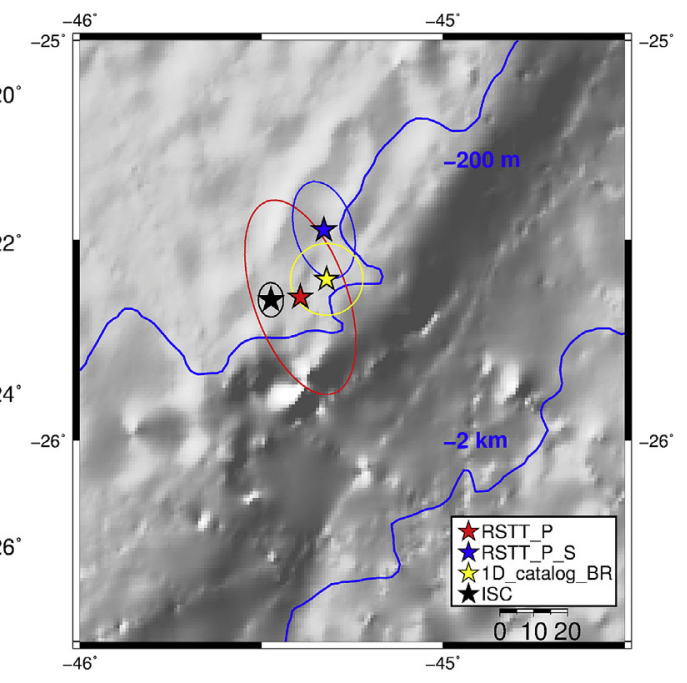

Fig. 6. (a) Map of relocated epicenters using the 3D RSTT model. (b) zoom on 2008 epicenters (white square on (a)), including the ISC location.

\section{Acknowledgments}

The work was carried out with CNPq grant 306547/2013-9, and the BRASIS project supported by the Petrobras Geotectonic Program, as part of the Brazilian Seismographic Network. We thank UnB for data from station SFA1. We also benefitted from a Comprehensive Nuclear-Test-Ban Treaty Organization workshop on the RSTT model, held in Costa Rica in 2015.

\section{References}

Assumpção, M., 1983. A regional magnitude scale for Brazil. Bull. Seism. Soc. Am. 73, 237-246.

Assumpção, M., 1998. Seismicity and stresses in the Brazilian passive margin. Bull. Seism. Soc. Am. 88 (1), 160-169.

Assumpção, M., Dourado, J.C., Ribotta, L.C., Mohriak, W.U., Dias, F.L., Barbosa, J.R., 2011. The São Vicente earthquake of April 2008 and seismicity in the continental shelf off se brazil: further evidence for flexural stresses. Geophys. J. Int. 187, 1076-1088. http://dx.doi.org/10.1111/j.1365-246X.2011.05198.x.

Assumpção, M., Bianchi, M.B., Julià, J., Dias, F.L., França, G.S., Nascimento, R.M., Drouet, S., Pavão, C.G., Albuquerque, D.F., Lopes, A.V., 2013a. Crustal thickness map of Brazil: data compilation and main features. J. South Am. Earth Sci. 43, 74-85. http://dx.doi.org/10.1016/j.jsames. 2012.12.009.

Assumpção, M., Feng, M., Tassara, A., Julià, J., 2013b. Models of crustal thickness for South America from seismic refraction, receiver functions and surface wave dispersion. Tectonophysics 609, 82-96. http://dx.doi.org/10.1016/j.tecto.2012.11.014.

Assumpção, M., Ferreira, J., Barros, L., Bezerra, F.H., França, G.S., Barbosa, J.R., Menezes, E., Ribotta, L.C., Pirchiner, M., Nascimento, A., Dourado, J.C., 2014. Intraplate seismicity in Brazil. In: Talwani, P. (Ed.), Intraplate Earthquakes, Chapter 3. 978-1-107-04038-0, Cambridge U.P.

Assumpção, M., Pirchiner, M., Dourado, J.C., Barros, L., 2016. Earthquakes in Brazil.
Preparing for rare events. Bull. Brazilian Geophys. Soc. Rio de Janeiro 96, 25-29.

Bondar, I., Storchak, D., 2011. Improved location procedures at the ISC. Geophys. J. Int. http://dx.doi.org/10.1111/j.1365-246X.2011.05107.x.

Bondar, I., Myers, S.C., Engdahl, E.R., Bergman, E.A., 2004. Epicentre accuracy based on the seismic network criteria. Geophys. J. Int. 156, 483-496.

Calais, E., Camelbeeck, T., Stein, S., Liu, M., Craig, T.J., 2016. A new paradigm for large earthquakes in stable continental plate interiors. Geophys. Res. Lett. http://dx.doi. org /10.1002/2016GL070815.

Chang, H.K., Kowsmann, R.O., Figueiredo, A.M.F., Bender, A., 1992. Tectonics and stratigraphy of the East Brazil rift System: an overview. Tectonophysics 213, 97-138.

Evain, M., Afilhado, A., Rigoti, C., Loureiro, A., Alves, D., Klingelhoefer, F., Schnurle, P. Feld, A., Fuck, R., Soares, J., Lima, M.V., Corela, C., Matias, L., Benabdellouahed, M., Baltzer, A., Rabineau, M., Viana, A., Moulin, M., Aslanian, D., 2015. Deep structure of the Santos basin-São Paulo plateau system, SE Brazil. J. Geophys. Res. Solid Earth 120. http://dx.doi.org/10.1002/2014JB011561.

Johnston, A.C., Kanter, L.R., 1990. Earthquakes in stable continental crust. Sci. Am. 262, 68-75.

Li, Q., Liu, M., Stein, S., 2009. Spatiotemporal complexity of continental intraplate seismicity: insights from geodynamic modeling and implications for seismic hazard estimation. Bull. Seism. Soc. Am. 99, 52-60.

Megies, T., Beyreuther, M., Barsch, R., Krischer, L., Wassermann, J., 2011. ObsPy what can it do for data centers and observatories? Ann. Geophys. 54 (1), 47-58. http://dx. doi.org/10.4401/ag-4838.

Myers, S., et al., 2010. A crust and upper mantle model of Eurasia and North Africa for Pn travel time calculation. Bull. Seism. Soc. Am. 100, 640-656.

Schulte, S.M., Mooney, W.D., 2005. An updated global earthquake catalogue for stable continental regions: reassessing the correlation with ancient rifts. Geophys. J. Int. $161,707-721$.

Zalan, P.V., Severino, M.C.G., Rigoti, C.A., Magnavita, L.P., Oliveira, J.A.B., Vianna, A.R., 2011. An entirely new 3D-view of the crustal and mantle structure of a south Atlantic passive margin - Santos, Campos and Espírito Santo basins, Brazil. In: AAPG Annual Convention, Houston TX, 2011, Extended Abstracts, Search and Discovery Article \#30177. 